\title{
Recent changes in the Arctic melt season
}

\author{
Julienne STROEVE, ${ }^{1}$ Thorsten MARKUS, ${ }^{2}$ Walter N. MEIER, ${ }^{1}$ Jeff MILLER ${ }^{1}$ \\ ${ }^{1}$ National Snow and Ice Data Center/University of Colorado, Campus Box 449, Boulder, CO 80309-0449, USA \\ E-mail: stroeve@kryos.colorado.edu \\ ${ }^{2}$ NASA Goddard Space Flight Center, Code 614.6, Bldg 33, Room A412, Greenbelt, MD 20771, USA
}

\begin{abstract}
Melt-season duration, melt-onset and freeze-up dates are derived from satellite passive microwave data and analyzed from 1979 to 2005 over Arctic sea ice. Results indicate a shift towards a longer melt season, particularly north of Alaska and Siberia, corresponding to large retreats of sea ice observed in these regions. Although there is large interannual and regional variability in the length of the melt season, the Arctic is experiencing an overall lengthening of the melt season at a rate of about 2 weeks decade ${ }^{-1}$. In fact, all regions in the Arctic (except for the central Arctic) have statistically significant (at the $99 \%$ level or higher) longer melt seasons by $>1$ week decade ${ }^{-1}$. The central Arctic shows a statistically significant trend (at the $98 \%$ level) of 5.4 days decade $^{-1}$. In 2005 the Arctic experienced its longest melt season, corresponding with the least amount of sea ice since 1979 and the warmest temperatures since the 1880s. Overall, the length of the melt season is inversely correlated with the lack of sea ice seen in September north of Alaska and Siberia, with a mean correlation of -0.8 .
\end{abstract}

\section{INTRODUCTION}

The last few years have seen a remarkable reduction in Arctic summer ice cover, with extensive retreats observed off the shores of Alaska and Siberia (Serreze and others, 2003; Stroeve and others, 2005). Since 1979, when routine satellite observations became available, the amount of area in the Arctic covered by sea ice during summer declined by over $20 \%$ (Fig. 1). In contrast to previous low ice years, when the summer ice tended to rebound the following year, the area covered by sea ice has remained low since 2002 and has resulted in an accelerated downward trend. In 2001 the trend was $-6.5 \%$ decade $^{-1}$. In 2002 it jumped to $-7.3 \%$ decade $^{-1}$ and by 2004 it was $-7.8 \%$ decade $^{-1}$. With a fourth consecutive year of substantial ice losses in 2005, the September seaice trend is now at a rate of $-8.5 \%$ decade $^{-1}$.

Annual average ice losses have been less, but this is changing. Although sea-ice extent during September 2002 and 2003 was substantially below the long-term mean of $7 \times 10^{6} \mathrm{~km}^{2}$, ice extent recovered to near its median position during the following winters. This was not the case following the 2004 September minima: ice extent remained low throughout the 2004/05 winter and spring, with record low extent observed in December-April (Meier and others, 2005). Also, in previous winters if the ice has retreated in one sector of the Arctic Ocean, it has generally advanced in another. Winter 2004/05 was unique in our 30 year history of passive microwave (PM) observations, in that the ice extent is within the median edge position everywhere, encompassing both the Pacific and Atlantic sectors, with the exception of a small area west of Iceland in February. This trend has continued into the 2005/06 winter. Statistically significant trends (at 99\% confidence) are now observed during both summer (July-September) and winter (November- January) at rates of $\sim-8 \%$ decade $^{-1}$ in summer and $\sim-3 \%$ decade $^{-1}$ in winter, suggesting that processes are leading to enhanced ice reduction during the summer and delayed freeze-up during the winter.

Earlier satellite data can extend the record back to about 1972, while aircraft reconnaissance and ship reports provide Arctic-wide information back to the early 1950s (e.g. HAD1SST dataset from Rayner and others, 2003). Although these assessments are less reliable than those based on the modern satellite record, they confirm that recent ice extents are likely the lowest in at least the past 50 years. Other regional assessments (e.g. Danish Meteorological Institute) imply that previous warm periods (1920s and 1930s) did not see reductions as great as the present ones. Additionally, since a generally cooler climate prevailed prior to 1900, the present sea-ice conditions are likely the lowest in the past several centuries.

The changes in ice cover are a result of both natural variability and anthropogenic forcing (Stroeve and others, 2005). However, feedbacks in the system appear to be sustaining the continual decline in the sea-ice cover (e.g. Lindsay and Zhang, 2005; Serreze and Francis, 2006). The primary feedbacks are related to changes in the melt season and retreat of the sea ice, exposing the open ocean which absorbs more solar energy and causes further warming. This ice-albedo feedback process is likely amplifying the effects of a general rise in Arctic temperatures. Overpeck and others

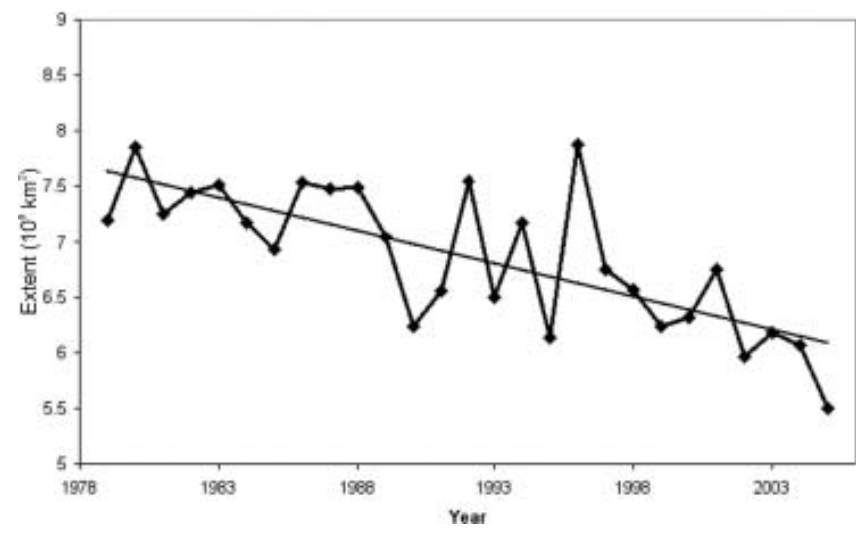

Fig. 1. Time series of monthly mean September sea-ice extent, 1979-2005. Ice extent is obtained by summing all pixels with at least $15 \%$ ice and assuming that the area near the pole that is not imaged by the sensor is $100 \%$ ice-covered. The linear least-squares trend is also included, showing a decline of $8.5 \%$ decade $^{-1}$ in September ice cover since 1979. Data available from the sea-ice index at http://nsidc.org. 
(2005) suggest that the Arctic system is moving towards a new state that will have substantially less summer ice than exists today. With the present rate of decline in the Arctic sea ice, speculation that the Arctic Ocean may become completely ice-free during summers within the present century appears to be realistic.

In order to improve our understanding of how changes in melt are affecting the trends in ice cover, a new melt/freeze algorithm was developed, and results from the algorithm were analyzed with respect to the September sea-ice cover. The reason a new melt algorithm was needed is that the two recent algorithms developed to determine melt over sea ice from PM data (e.g. Smith, 1998; Drobot and Anderson, 2001) do not provide estimates of melt-onset and freeze-up dates for the entire Arctic. The Advanced Horizontal Range Algorithm (AHRA) from Anderson (1997) and modified by Drobot and Anderson (2001) only provides melt-onset dates, while the Smith (1998) algorithm calculates melt and freeze onset but is only applicable for perennial ice. Belchansky and others (2004) used a combination of PM and International Arctic Buoy Program/Polar Exchange at the Sea Surface (IABP/POLES: Rigor and others, 2000) surface air temperatures (SATs) to derive a melt/freeze product that was limited to the time period of the IABP/POLES data (e.g. 1979-2000). A problem with the use of the IABP/POLES data, however, is that the IABP/POLES SATs are a large-scale estimate of the SAT field and are unable to capture the smallscale patterns of freeze/melt as a result of dynamic (e.g. wind) sea-ice growth and decay that can be observed from satellite. Therefore, the Belchansky and others (2004) algorithm is better suited for the central Arctic. Thus, in order to examine the melt season from 1979 to 2005 for the entire Arctic, a new algorithm was needed. This paper describes the new melt algorithm and summarizes regional and interannual variability in the timing of melt onset, freeze-up and melt duration from 1979 to 2005.

\section{METHODOLOGY}

Observations from multichannel satellite PM since the late 1970s provide the basis for the analysis, specifically, data from the Nimbus-7 Scanning Multichannel Microwave Radiometer (SMMR: 1978-87) and the ongoing series of US Defense Meteorological Satellite Program (DMSP) Special Sensor Microwave/Imagers (SSM/I: 1987-2005). These data are used to summarize sea-ice extent and the timings of when melt begins and ice refreezes. Sea-ice extent is derived using sea-ice concentrations from the NASA Goddard Space Flight Center dataset that utilizes the NASA-Team sea-ice algorithm applied to the SMMR and SSM/I brightness temperatures (Cavalieri and others, 2002) and is archived by the US National Snow and Ice Data Center (http://nsidc.org). To derive the ice extent, all pixels with at least $15 \%$ sea ice are summed and multiplied by the area per pixel.

Melt and freeze-up are determined using a new algorithm referred to here as the PMW algorithm. The timing of melt onset can be detected using PM brightness temperatures ( $T b$ 's) because emissivity changes when liquid water forms in the snowpack that overlies the sea ice. The difference between dry and wet snow is greatest at $37 \mathrm{GHz}$. Our approach is based on a combination of the AHRA and the Smith (1998) method, using PM brightness temperatures to compute both the melt onset and freeze-up dates. Following
Smith (1998), a value $P$ is calculated using Tb's at $19 \mathrm{~V} \mathrm{GHz}$ and $37 \mathrm{~V} \mathrm{GHz}$, and used as a threshold in both melt-onset and freeze-up date computations for each pixel:

$$
P=\operatorname{Tb}(19 \mathrm{~V})+0.8 \mathrm{~Tb}(37 \mathrm{~V}) .
$$

In Smith (1998), the $P$ value indicates melt when $P$ becomes greater than 460, and indicates freeze-up when $P$ becomes less than 425. These thresholds can only be used for areas of multi-year ice as observed in the central Arctic because $P$ is correlated with sea-ice concentration. To calculate melt and freeze-up dates for the entire Arctic requires additional information. Specifically, we included the polarization ratio at $19 \mathrm{GHz}(\mathrm{PR}(19))$, the spectral gradient ratio of 37 and $19 \mathrm{GHz}$ vertical polarization (GR) and the daily difference in $37 \mathrm{~V}$ brightness temperatures. The GR values are needed to distinguish between ice-covered and ice-free ocean and to monitor the commencement and disintegration of the seaice cover. $\mathrm{PR}(19)$ and the daily change in $\mathrm{Tb}(37 \mathrm{~V})$ together with the $P$ value help to retrieve more consistent melt and freeze days. For perennial sea ice, $\mathrm{PR}(19)$ typically reaches its maximum when the ice refreezes. The use of $\mathrm{Tb}(37 \mathrm{~V})$ is similar to work by Belchansky and others (2004), but instead of using horizontal polarization Tb's for freezing periods, we used $\mathrm{Tb}(37 \mathrm{~V})$ because it is relatively stable (e.g. less impacted by snowpack features such as depth hoar and ice lenses), but still shows large sensitivity to the timings of when melt begins and ice refreezes. Thus, the two main criteria for the detection of melt onset are (1) daily fluctuations in $\mathrm{Tb}(37 \mathrm{~V})$ of $4 \mathrm{~K}$ and (2) $P$-value threshold. GR37/19 is primarily used as an indicator of the fraction of sea ice per pixel. Because the Smith (1998) algorithm was developed for SSM/I, we regressed SMMR Tb's towards SSM/ I using the 1987 overlap period for consistency.

Temporal evolution of the microwave signatures together with the IABP/POLES and US National Centers for Environmental Prediction/US National Center for Atmospheric Research (NCEP/NCAR) SATs for both seasonal and perennial ice is shown in Figure 2. The two ice types show distinctly different temporal signatures. While ice concentration is variable for seasonal sea ice, it stays close to $100 \%$ for perennial ice. For seasonal sea ice, melt onset is determined when $P$ falls below $440 \mathrm{~K}$ and daily changes in $\mathrm{Tb}(37 \mathrm{~V})$ are greater than $4 \mathrm{~K}$. From Figure 2 it is apparent that these two criteria disagree slightly for the particular seasonal ice pixel examined. This is because after a short period of melt on day 143 (see IABP/POLES data), the temperature drops again. In the current version of the algorithm, the $P$ value dominates the $\mathrm{Tb}(37 \mathrm{~V})$ change so that the final melt onset is later. The PMW melt onset for this seasonal ice example agrees with the $-5^{\circ} \mathrm{C}$ threshold used in the IABP/POLES data to determine melt. Note the NCEP/ NCAR temperatures are significantly higher throughout the year. Freeze-up for seasonal ice is typically later than what the air temperatures suggest because the ocean water temperature needs to reach the freezing temperature before ice forms. Nevertheless, the different microwave parameters show a coherent sea-ice signature, and freeze-up is primarily determined by the formation of sea ice.

For perennial sea ice the situation is different. Ice concentration remains high throughout the summer. Melt onset is determined similar to the way it is determined in Smith (1998) by using a $P$ value greater than $460 \mathrm{~K}$ to indicate the onset of melt. Here, the change in $\mathrm{Tb}(37 \mathrm{~V})$ is consistent with the $P$ value. There is also a simultaneous jump in the 

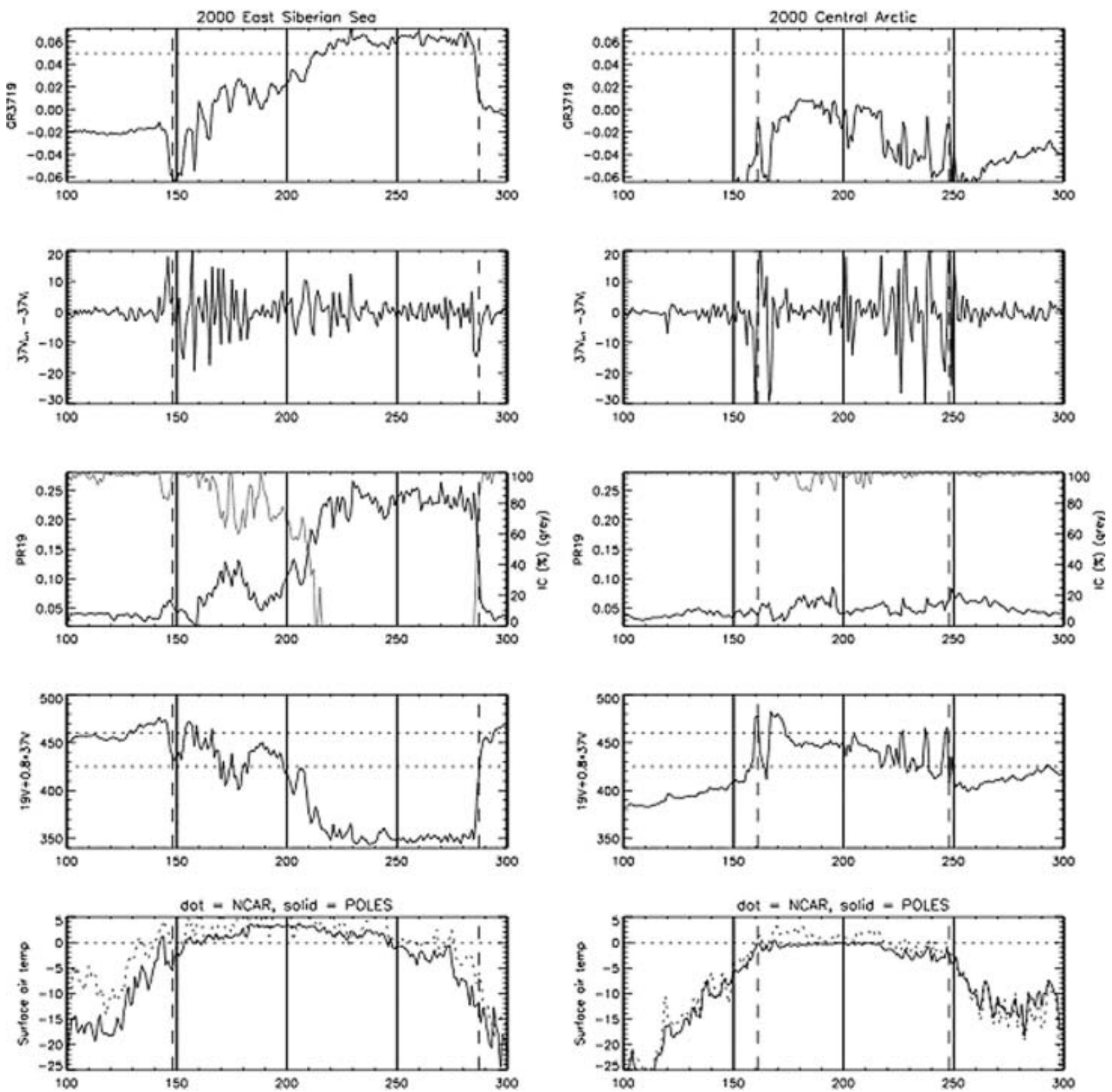

Fig. 2. Temporal evolution of microwave signatures for seasonal sea ice (left column) and for perennial sea ice (right column). The dashed vertical lines indicate the onset of melt and freeze, respectively, as identified by the algorithm. Sea-ice concentration is shown in the PR19 plot (light gray line).

GR37/19 towards 0, indicative of the black-body behavior of a wet snow surface. When the sea ice refreezes, three distinct peaks in the $P$ value and the daily change in $\mathrm{Tb}(37 \mathrm{~V})$ (between days 225 and 250) are observed, which correspond to three peaks in the IABP/POLES temperatures (the IABP/ POLES temperatures never reach $0^{\circ} \mathrm{C}$ in these daily averages). Frequently, there is a transition period where initial freeze is followed by intermittent warmer periods. The actual freeze onset day is determined by the last jump in the $P$ value, which generally coincides with a maximum in the $\mathrm{PR}(19)$. In this example, the melt onset for perennial sea ice corresponds with the time of year when the IABP/POLES SAT data reach $0^{\circ} \mathrm{C}$, and the freeze-up dates agree with the last day the $\mathrm{NCEP} / \mathrm{NCAR}$ and IABP/POLES data are greater than $-3^{\circ} \mathrm{C}$. It is interesting to note that the NCEP/NCAR temperatures are in better agreement with the IABP/POLES temperatures for perennial sea ice than they are for seasonal ice.
Validation of melt-onset and freeze-up dates remains a difficult task. Different melt-onset dates will be found depending on the method and/or sensor used. Melt-onset algorithms based on surface temperature or albedo thresholds or using active microwave data will all give different melt-onset and freeze-up dates because they are responding to different physical properties. For example, melt onset from PM is based on the date when moisture first appears in the snowpack, which does not necessarily coincide with above-freezing surface air temperatures. Additionally, there is a lack of robust validation data to access the accuracy of any melt detection algorithm. Our results using the method described above show reasonable agreement with the Smith (1998) results for perennial ice (not shown), the IABP/POLES and NCEP/NCAR SATs, and the melt-onset dataset from the AHRA (Fig. 3). The IABP/POLES and NCEP retrievals are based on the dates when the temperatures rise above $-5^{\circ} \mathrm{C}$ 


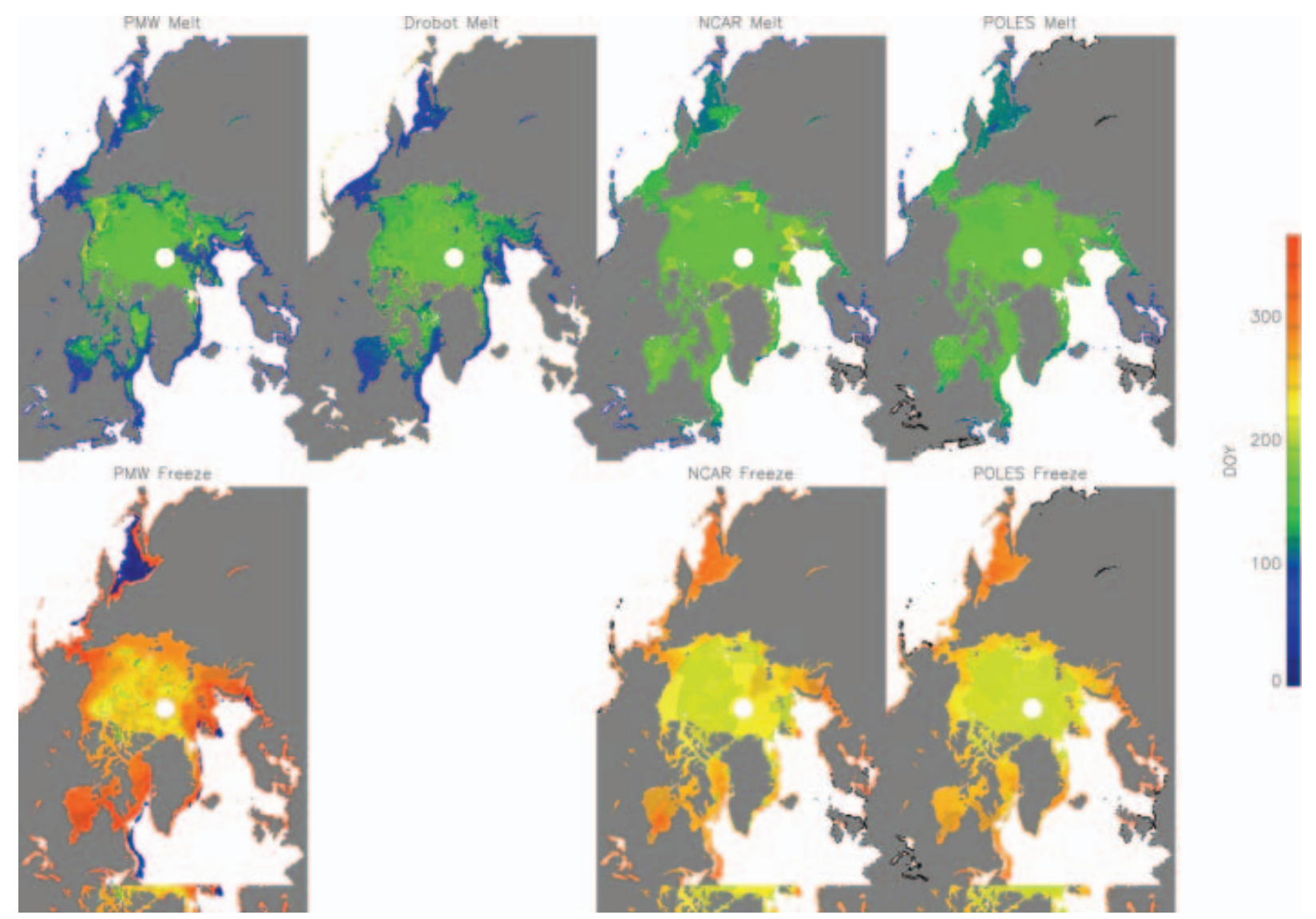

Fig. 3. Melt-onset and freeze-up days computed by the PMW algorithm, the AHRA algorithm (e.g. Drobot and Anderson, 2001) and by the NCAR and IABP/POLES surface air temperatures. The blue areas in the PWM freeze image correspond to regions where freeze-up occurred the following year.

and then fall back to below $-5^{\circ} \mathrm{C}$, as in Belchansky and others (2004). Our melt-onset dates lie in between the IABP/ POLES and NCEP/NCAR dates and are also in agreement with work by Nicolaus and others (2006) who used the SNTHERM model (Jordan, 1991) to determine when the first meltwater reaches the snow/ice interface.

Figure 4 compares interannual variability of melt-onset and freeze-up dates for the central Arctic from PMW, AHRA, NCEP/NCAR and IABP/POLES SATs. Good overall correlation in melt trends and interannual variability is found between the AHRA, the NCEP/NCAR SATs and the PMW results. The PMW melt-onset dates show a 0.71, 0.53 and 0.43 correlation respectively with the AHRA, the IABP/ POLES and the NCEP/NCAR SAT data. The correlation for melt-onset day between AHRA and IABP/POLES and NCEP/ NCAR SATs is 0.26 and 0.33 , respectively. For freeze-up, the correlation between IABP/POLES SATs and PMW is 0.22 , and for NCEP/NCAR and PMW it is 0.4. The mean difference between PMW and the AHRA melt-onset dates is 11 days (with AHRA indicating mostly later melt), and the mean difference between PMW and IABP/POLES (NCEP/NCAR) is 20 (17) days, with IABP/POLES and NCEP/NCAR showing mostly earlier melt onset. These comparisons suggest that, at least for melt in the central Arctic, a temperature threshold closer to $0^{\circ} \mathrm{C}$ would bring the PM results and the results based on surface air temperature in closer agreement. A quantitative comparison for the outer seas is more difficult, as the dynamic appearance and disappearance of sea ice is not necessarily highly correlated with the temperature fields (see also Figs 2 and 3).
Overall, we note the accuracy is better for the central Arctic than for the marginal seas because sea-ice dynamics and ocean currents can strongly affect the presence or absence of the sea-ice cover in the marginal seas. For example, a dynamic retreat of sea ice, particularly in the marginal sea-ice zone, would be interpreted as melt onset. Correspondingly the appearance of sea ice would be interpreted as onset of freeze, independent of whether it has formed thermodynamically or dynamically. In the following, we limit our discussions of melt-season changes to the following Arctic regions: central Arctic, Beaufort Sea, Chukchi/East Siberian Sea, the Laptev, Kara and Barents Seas (see Fig. 5), realizing dynamical effects may still have some impact on the melt and freeze dates presented below.

\section{CHANGES IN THE MELT SEASON}

Figure 6 summarizes the climatological mean (e.g. 19792005) length of the melt season, together with the mean meltseason duration in the 1980s, 1990s and 2000s. Also shown are the mean melt-onset and freeze-up dates for the same time periods. Results indicate a large shift in the length of the melt season since the 1980s, with the season lasting longer in the peripheral seas and north of Alaska and Siberia. This shift is influenced both by a shift towards earlier melt-onset dates and by later freeze-up dates. Overall, the length of the sea-ice melt season has increased by more than 3 weeks throughout the Northern Hemisphere since 1979. This change in the melt season is largely a result of a basin-wide shift towards earlier melt-onset dates by $>1$ week decade ${ }^{-1}$, so that melt 

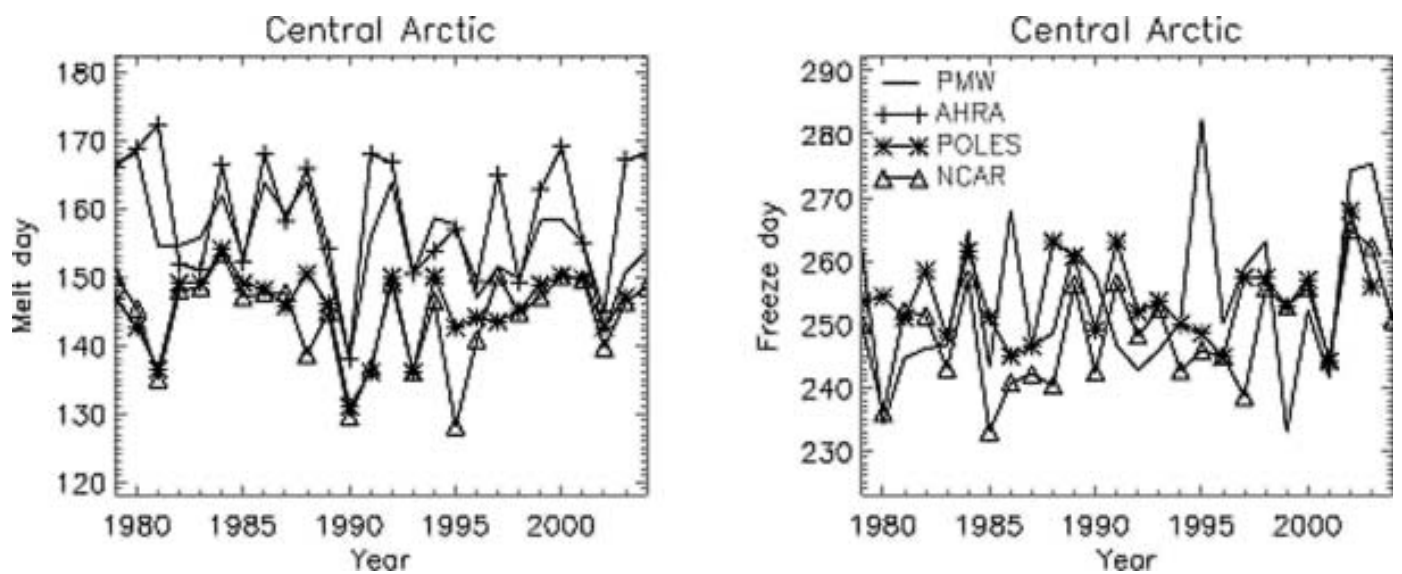

Fig. 4. Melt- (a) and freeze-onset (b) dates for the central Arctic from PWM, AHRA, NCEP/NCAR and IABP/POLES SATs. The IABP/POLES and NCEP/NCAR retrievals are based on the dates when the temperatures rise above $-5^{\circ} \mathrm{C}$ and then fall back to below $-5^{\circ} \mathrm{C}$.

now begins on average 13 days earlier in the 2000s than it did in the 1980s. Belchansky and others (2004) previously reported on the differences in the melt season between the 1980 s and 1990s. While our results also indicate statistically significant differences in the melt season between the $1980 \mathrm{~s}$ and the 1990s, we also found significant differences between the 1990s and the 2000s. The central Arctic, the Chukchi/East Siberian Sea and the Kara Sea experienced on average 6 more days of melt in 2000-05 than they did in 1990-99, and the Greenland Sea had 11 more days of melt (or absence of sea ice) in the 2000s than it did in the 1990s.

The longest melt season since the late 1970s occurred in 2005, coinciding with the largest ice losses observed since 1979 (see Fig. 1) and the warmest year since the 1880s (http:// data.giss.nasa.gov/gistemp/2005/). Regionally (see Fig. 7), 2005 was the year of the longest melt season (more than two standard deviations from the mean) for the central Arctic (121 days) and the Chukchi/East Siberian Seas (167 days). It was in these same regions that the ice pack significantly retreated in 2005. In the Beaufort Sea, the longest melt seasons are found in 2004 and 1998, lasting 166 days (34 days longer than normal). These years also showed unusual ice losses in the Beaufort Sea. Similarly, 1995 was a record melt year for the Laptev and Kara Seas, with a melt season that lasted 167 and 187 days, respectively (more than two standard deviations from the mean), and that year the summer ice significantly retreated off the shores of Siberia. Thus, the pattern in melt-season duration is qualitatively consistent with the spatial pattern of ice losses observed that

Table 1. Correlation coefficients between the amount of sea ice in September and the timings of when melt begins and ice refreezes and the length of the melt season

\begin{tabular}{lrcc}
\hline Region & Melt onset & Freeze-up & $\begin{array}{c}\text { Melt-season } \\
\text { duration }\end{array}$ \\
\hline Central Arctic & -0.13 & -0.14 & -0.01 \\
Beaufort & 0.55 & -0.77 & -0.78 \\
Chukchi/East Siberian & 0.60 & -0.78 & -0.82 \\
Laptev & 0.59 & -0.81 & -0.77 \\
Kara & -0.11 & -0.71 & -0.34 \\
Barents & 0.03 & 0.02 & -0.18 \\
\hline
\end{tabular}

year. We can quantify how changes in the melt season affect the summer ice cover by looking at the correlation between the annual melt onset, freeze-up and melt duration and the September sea-ice concentration for each region. In general, there is a strong inverse correlation between the length of the melt season and the amount of sea ice left in September, where years with low sea ice correspond to years with longer melt seasons (Table 1). This is true for the Beaufort, Chukchi, East Siberian and Laptev Seas, where the correlation coefficients are all around -0.8. Little or no correlation between the length of the melt season and the amount of sea ice in September is found for the central Arctic, and the Kara and Barents Seas. Freeze-up dates are also strongly correlated $(0.7-0.8)$ with the amount of September sea ice for all regions except the central Arctic and the Barents Sea, whereas the timing of melt onset shows somewhat less correlation with ice conditions at the end of summer.

Although there is substantial regional and interannual variability in the melt season, results show a clear shift towards a longer melt season throughout the Arctic. Interestingly, the largest changes in the melt season are found in

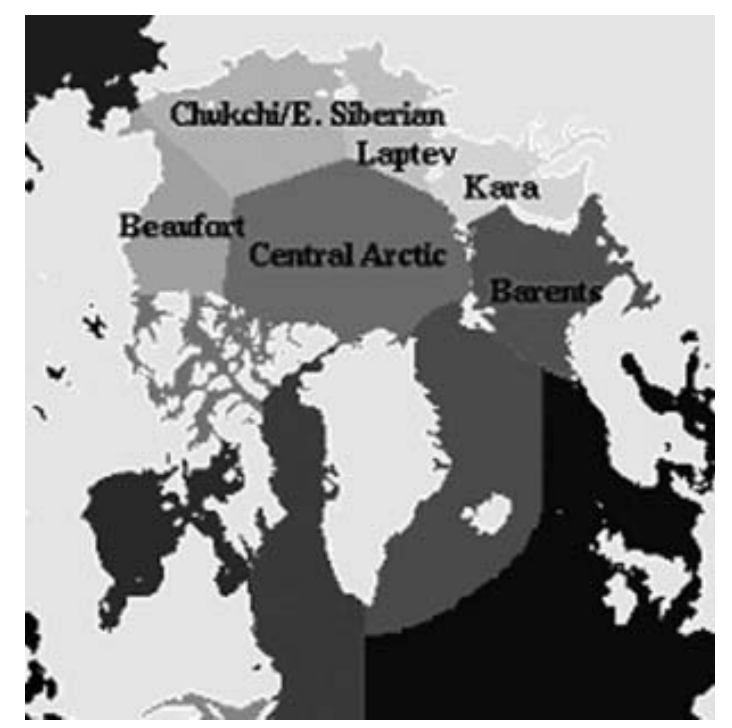

Fig. 5. Sectional mask of the Arctic showing the regions of the Arctic to be used in the evaluation of changes in the Arctic sea-ice melt season. 

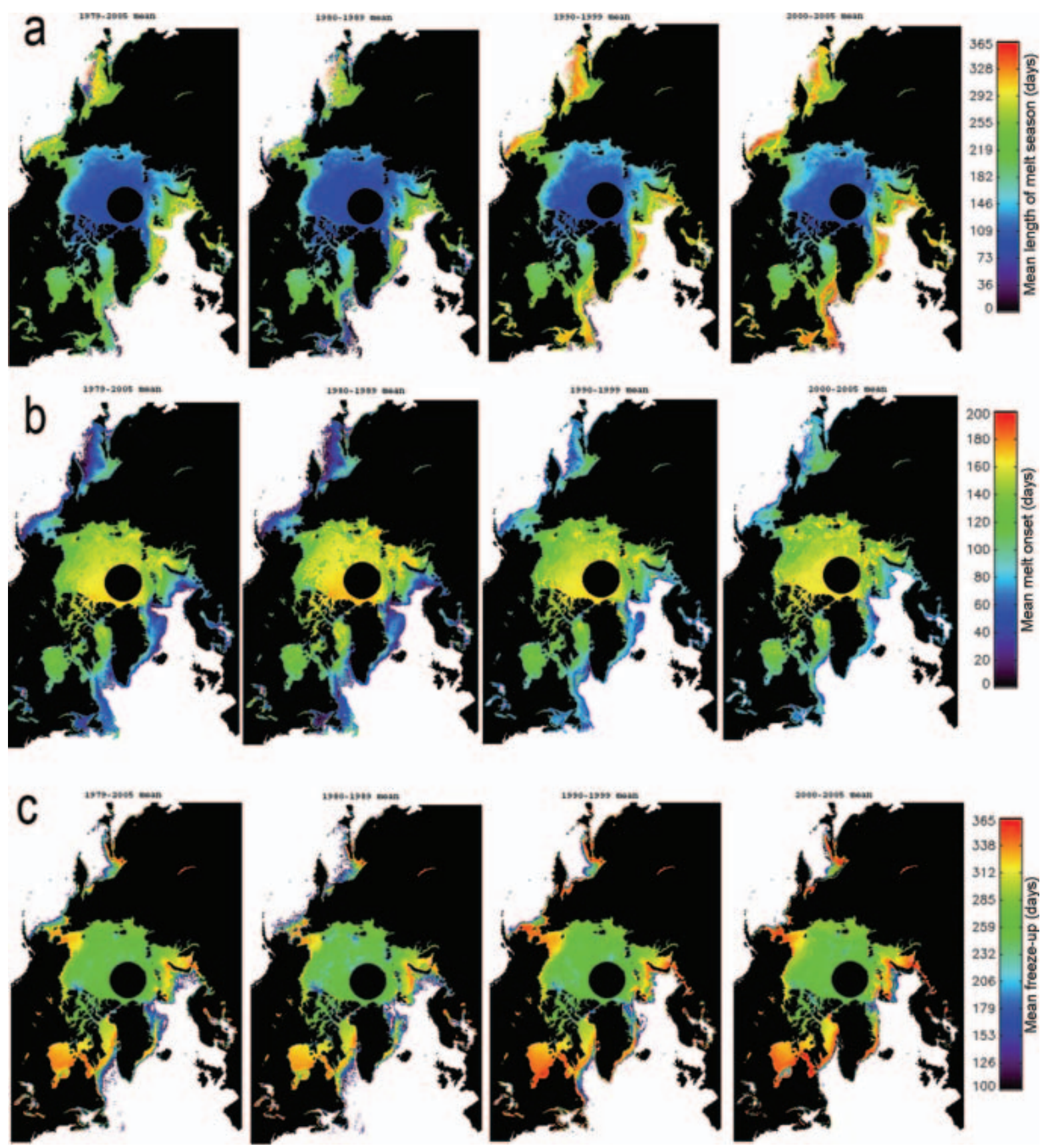

Fig. 6. Mean duration of melt (a), melt-onset (b) and freeze-up (c) dates computed from (left to right) the long-term average, the 1980s (1980-89), the 1990s (1990-99) and the 2000s (2000-05). Early freeze-up dates along the ice margin reflect the fact that the ice froze in those areas after the first of the year, and therefore imply a later freeze-up date (not an early one).

the eastern Arctic (e.g. Kara and Barents Seas) where the melt-season duration has increased by $>2$ weeks decade ${ }^{-1}$ (see Table 2). This change is largely a result of the trend towards earlier melt onset and is similar to results reported by Belchansky and others (2004) using data through 2001. In the Beaufort, Chukchi and East Siberian Seas, the melt season increased by $>1$ week decade ${ }^{-1}$. With the inclusion of the 2005 record melt year, the central Arctic shows a statistically significant trend towards a longer melt season (at a rate of 5.4 days decade ${ }^{-1}$ at the $98 \%$ confidence level).

Belchansky and others (2004) discussed the change in melt-onset, freeze-up and duration dates between the years prior to the 1989 Arctic Oscillation (AO) phase shift (197988) and the years following (1989-2001). While it is not possible to fully compare our results to theirs as we have slightly different regional delineations, we show similar magnitudes of changes in the melt season between the pre- and post-positive $\mathrm{AO}$ shift on the order of a 1-3 weeks longer melt season, with the largest shift found in the eastern Arctic. Since the study by Belchansky and others (2004), the $\mathrm{AO}$ has returned to a more neutral (and at times negative) state. However, results here show the melt season has continued to lengthen past the positive AO state of the 1990s.

Belchansky and others (2004) also associated the more variable melt durations since 1988 with the shift to the positive AO state of the 1990s. During the low-AO state, Belchansky and others (2004) argued that dominant anticyclonic conditions would have maintained a cooler and more uniform climate and hence less variable melt seasons. Results here also show that melt became more variable 
(together with the sea-ice extent) after 1989 (the Barents Sea is an exception). However, despite a return to a more neutral AO state, melt durations have remained more variable than they were prior to 1989 , providing further evidence that the previous association with the AO may no longer hold. Updating the analysis by Belchansky and others (2004) using melt data through 2005, we find that only the melt-season durations in the Laptev and Barents Seas have statistically significant correlations with the $\mathrm{AO}$, of 0.38 (at $98 \%$ confidence) and 0.44 (at 99\% confidence), respectively. These correlations are much lower than previously reported in Belchansky and others (2004). Furthermore, freeze distributions using data through 2005 do not indicate a return to those observed under low-index $\mathrm{AO}$ conditions as previously suggested by Belchansky and others (2004).

\section{CONCLUSIONS}

The Arctic is warming rapidly, showing an annual average Arctic temperature trend that is nearly twice that of the rest of the Earth over the last few decades. Increasing global concentrations of $\mathrm{CO}_{2}$ and other greenhouse gases from human activities are projected to cause further warming in the Arctic of $4-7^{\circ} \mathrm{C}$ over the next century (ACIA, 2005). This warming will lead to continued decreases in the sea-ice cover, with dire consequences for the local communities and wildlife that depend on the sea ice for their existence. In this study, we expanded on previous efforts to monitor changes in the melt season over Arctic sea ice by building an algorithm based on the PM satellite record that determines both melt onset and freeze-up for the entire Arctic without relying on SAT data from other sources. Using satellite PM data for monitoring Arctic melt ensures a consistent product.

Results from the algorithm show a clear shift in the meltseason duration since the late 1970s, resulting from both earlier melt-onset and later freeze-up dates in the last several years. Previously Belchansky and others (2004) indicated the melt season in the Siberian Arctic was strongly correlated to the AO. However, in the last few years the low ice years are not consistent with high-index $\mathrm{AO}$ conditions, and the connection with the $\mathrm{AO}$ has weakened, suggesting the trends in recent years towards earlier melt and later freeze in both the Siberian and Alaskan sectors are a result of other processes. Examining weather patterns in recent summers shows that each year has had different patterns of airflow, high and low pressure and precipitation. The one common thread is that Arctic temperatures over the ice, ocean and
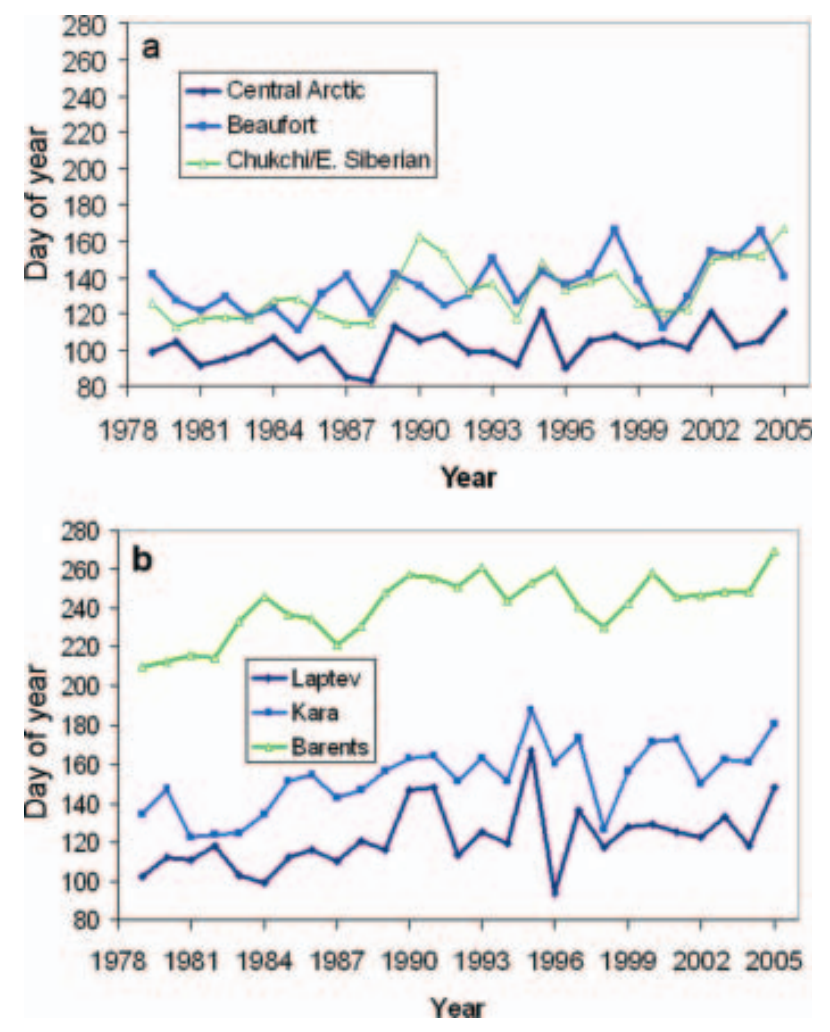

Fig. 7. Mean melt-season duration for the western Arctic (a) and the eastern Arctic (b).

surrounding land have increased (e.g. Comiso, 2003). As temperatures rise, less ice grows in autumn and winter, and the summer melt season becomes longer. More of the dark ocean surface is exposed, which readily absorbs solar radiation, leading to even less ice growth the next autumn and winter. Available satellite data confirm a longer melt season and an accelerated decline in the amount of summer sea ice. However, given that other records point to considerable decadal and multi-decadal variability in the Arctic system, one cannot discount the possibility that the sea ice will rebound in coming years.

\section{ACKNOWLEDGEMENTS}

This paper was funded under NASA grant No. NNG04GO51G. The sea-ice concentration and PM brightness temperature data are available from the NSIDC. We thank the reviewers for their thorough evaluation of the paper.

Table 2. Trends in melt onset, freeze-up and length of melt season (days decade ${ }^{-1}$ ). Included are the values of the mean melt onset, freeze-up and melt duration (standard deviation given in parentheses). Values in boldface are statistically significant at the $98 \%$ or higher confidence interval

\begin{tabular}{|c|c|c|c|c|c|c|}
\hline Region & $\begin{array}{c}\text { Melt } \\
\text { onset trend }\end{array}$ & $\begin{array}{l}\text { Freeze-up } \\
\text { trend }\end{array}$ & $\begin{array}{c}\text { Duration of } \\
\text { melt-season trend }\end{array}$ & $\begin{array}{c}\text { Mean } \\
\text { melt onset }\end{array}$ & $\begin{array}{l}\text { Mean } \\
\text { freeze-up }\end{array}$ & $\begin{array}{c}\text { Mean } \\
\text { melt-season duration }\end{array}$ \\
\hline Central Arctic & -3.9 & 1.5 & 5.4 & $158.5(5.9)$ & $258.6(6.6)$ & $102.2(9.8)$ \\
\hline Beaufort & -4.7 & 4.9 & 9.2 & $142.3(8.4)$ & $276.0(9.4)$ & $132.5(14.5)$ \\
\hline Chukchi/East Siberian & -4.6 & 6.9 & 11.8 & $144.4(8.3)$ & $274.0(7.6)$ & $129.2(13.6)$ \\
\hline Laptev & -4.1 & 5.3 & 9.7 & $148.4(9.8)$ & $270.8(8.5)$ & $122.2(16.5)$ \\
\hline Barents & -8.8 & 6.5 & 16.9 & $105.1(11.6)$ & $316.6(17.4)$ & $246.8(17.5)$ \\
\hline
\end{tabular}




\section{REFERENCES}

Anderson, M.R. 1997. Determination of a melt-onset date for Arctic sea-ice regions using passive-microwave data. Ann. Glaciol., 25, 382-387.

Arctic Climate Impact Assessment (ACIA). 2005. Arctic Climate Impact Assessment. Cambridge, etc., Cambridge University Press.

Belchansky, G.I., D.C. Douglas and N.G. Platonov. 2004. Duration of the Arctic melt season: regional and interannual variability, 1979-2001. J. Climate, 17(1), 67-80.

Cavalieri, D.J., C. Parkinson, P. Gloersen and H.J. Zwally. 2002. Sea ice concentrations from Nimbus-7 SMMR and DMSP SSM/I passive microwave data, June to September 2001. Boulder, CO, National Snow and Ice Data Center. CD-ROM.

Comiso, J.C. 2003. Warming trends in the Arctic from clear satellite observations. J. Climate, 16(21), 3498-3510.

Drobot, S.D. and M.R. Anderson. 2001. An improved method for determining snowmelt onset dates over Arctic sea ice using scanning multichannel microwave radiometer and Special Sensor Microwave/Imager data. J. Geophys. Res., 106(D20), 24,033-24,050.

Jordan, R. 1991. A one-dimensional temperature model for a snow cover: technical documentation for SNTHERM.89. CRREL Spec. Rep. 91-16.

Lindsay, R.W. and J. Zhang. 2005. The thinning of Arctic sea ice,
1988-2003: have we passed a tipping point? J. Climate, 18(22), 4879-4894.

Meier, W., J. Stroeve, F. Fetterer and K. Knowles. 2005. Reductions in Arctic sea ice cover no longer limited to summer. EOS Trans. $A G U, \mathbf{8 6}(36), 326-327$.

Nicolaus, M., C. Haas, J. Bareiss and S. Willmes. 2006. A model study of differences of snow thinning on Arctic and Antarctic first-year sea ice during spring and summer. Ann. Glaciol., 44 (see paper in this volume).

Rayner, N.A. and 7 others. 2003. Global analyses of sea surface temperature, sea ice, and night marine air temperature since the late nineteenth century. J. Geophys. Res., 108(D14), 4407. (10.1029/2002JD002670.)

Rigor, I.G., R.L. Colony and S. Martin. 2000. Variations in surface air temperature observations in the Arctic, 1979-97. J. Climate, 13(5), 896-914.

Serreze, M.C. and J.A. Francis. 2006. The Arctic amplification debate. Climatic Change, 76(3-4), 241-264.

Serreze, M.C. and 9 others. 2003. A record minimum Arctic sea ice extent and area in 2002. Geophys. Res. Lett., 30(3), 1110. (10.1029/2002GL016406.)

Smith, D.M. 1998. Observation of perennial Arctic sea ice melt and freeze-up using passive microwave data. J. Geophys. Res., 103(C12), 27,753-27,769.

Stroeve, J.C. and 6 others. 2005. Tracking the Arctic's shrinking ice cover: another extreme September minimum in 2004. Geophys. Res. Lett., 32(4), L04501. (10.1029/2004GL021810.) 